\title{
Child health, infant formula funding and South African health professionals: Eliminating conflict of interest
}

\author{
L Lake, ${ }^{1}$ BA Hons; M Kroon, ${ }^{2}$ MB ChB, FC Paed (SA); D Sanders, ${ }^{3,4}$ MB ChB, MRCP, DCH, DTPH, DSc; A Goga, ${ }^{5,6}$ MB ChB, FC Paed (SA); \\ C Witten, ${ }^{7}$ BSc (Dietetics), MSc (Nutrition); R Swart, ${ }^{8}$ BSc (Dietetics), MPhil (Public Health), PhD; H Saloojee, ${ }^{9}$ MB ChB, FC Paed (SA); \\ C Scott, ${ }^{10}$ MB ChB, FC Paed (SA); M Manyuha, ${ }^{11}$ BSc (Dietetics); T Doherty, ${ }^{3,5,12}$ B Nursing, MSc (Nursing), MPH, PhD \\ ${ }^{1}$ Children's Institute, University of Cape Town, South Africa \\ ${ }^{2}$ Department of Neonatology, Faculty of Health Sciences, University of Cape Town and Mowbray Maternity Hospital, Cape Town, South Africa \\ ${ }^{3}$ School of Public Health, Faculty of Community and Health Sciences, University of the Western Cape, Cape Town, South Africa \\ ${ }^{4}$ Department of Paediatrics and Child Health, Faculty of Health Sciences, University of Cape Town, South Africa \\ ${ }^{5}$ Health Systems Research Unit, South African Medical Research Council, Cape Town and Pretoria, South Africa \\ ${ }^{6}$ Department of Paediatrics, School of Medicine, Faculty of Health Sciences, University of Pretoria, South Africa \\ ${ }^{7}$ School of Physiology, Nutrition and Consumer Sciences, Faculty of Health Sciences, North-West University, Potchefstroom, South Africa \\ ${ }^{8}$ Department of Dietetics and Nutrition, Faculty of Community and Health Sciences, University of the Western Cape, Cape Town, South Africa \\ ${ }^{9}$ Department of Paediatrics and Child Health, Faculty of Health Sciences, University of the Witwatersrand, Johannesburg, South Africa \\ ${ }^{10}$ Paediatric Rheumatology, Department of Paediatrics and Child Health, Faculty of Health Sciences, University of Cape Town and Red Cross War \\ Memorial Children's Hospital, Cape Town, South Africa \\ ${ }^{11}$ Nutrition Directorate, National Department of Health, Pretoria, South Africa \\ ${ }^{12}$ School of Public Health, Faculty of Health Sciences, University of the Witwatersrand, Johannesburg, South Africa
}

Corresponding author: T Doherty (tanya.doherty@mrc.ac.za)

\begin{abstract}
Despite clear evidence of the benefits of exclusive and continued breastfeeding for children, women and society, far too few children in South Africa (SA) are breastfed. One of the major impediments to improving this situation is the continued and aggressive marketing of breastmilk substitutes (BMSs) and infiltration of the BMS industry into contexts with exposure to health professionals. In this article we, as academics, practitioners and child health advocates, describe contraventions of the regulations that protect breastfeeding in SA and argue that bold, proactive leadership to eliminate conflict of interest in respect of the BMS industry is urgently required, together with far greater investments in proven interventions to promote and support breastfeeding.
\end{abstract}

S Afr Med J 2019;109(12):902-906. https://doi.org/10.7196/SAMJ.2019.v109i12.14336

The continued and aggressive marketing of breastmilk substitutes (BMSs) is a considerable impediment to improving breastfeeding. In this 'In Practice' article we, as academics, practitioners and child health advocates, describe contraventions of the regulations that protect breastfeeding in South Africa (SA) and argue that bold, proactive leadership to eliminate conflict of interest in respect of the BMS industry is urgently required, together with far greater investments in proven interventions to promote and support breastfeeding.

The 2016 Lancet Breastfeeding Series estimated that improved breastfeeding practices could prevent $72 \%$ of hospital admissions for diarrhoea and $57 \%$ for respiratory infections in low- and middleincome countries, and could have averted 823000 deaths in the 75 Countdown countries in 2015. ${ }^{[1]}$ Yet despite clear evidence of the benefits of exclusive and continued breastfeeding for children, women and society, far too few children in SA are breastfed. There is some urgency to improve breastfeeding rates in view of the profound life-course effects of breastfeeding on human health and all the Sustainable Development Goals. ${ }^{[2]}$

In an effort to protect breastfeeding and respond to growing evidence of aggressive and inappropriate marketing strategies of BMS companies, ${ }^{[3,4]}$ the 34th World Health Assembly in 1981 adopted Resolution WHA34.22, which included the International Code of Marketing of Breast-milk Substitutes ('the Code') as a 'minimum requirement' to be adopted 'in its entirety' (118 nations voted in favour, and only the USA voted against). In 1982 Peru became the first country to adopt the Code as national legislation. Globally, 136 out of 194 countries have Code-related legislation, yet contraventions and violations persist in the face of weak monitoring and enforcement mechanisms. ${ }^{[5]}$

In 2012, SA legislated the Code through the Regulations Relating to Foodstuffs for Infants and Young Children (R991) ${ }^{[6]}$ in terms of section 15(1) of the Foodstuffs, Cosmetics and Disinfectants Act, Act 54 of $1972,{ }^{[7]}$ following the Tshwane Declaration of Support for Breastfeeding. ${ }^{[8]}$ R991 aims to protect and promote breastfeeding by regulating the inappropriate marketing of BMSs to 'remove commercial pressures from the infant feeding arena, 'avoid creating any conflicts of interest or perverse incentives for individual health professionals' and 'ensure that financial support for professionals working in infant and young child health does not create conflicts of interest'.

\section{History of breastfeeding in SA}

SA has a complex policy history of protection and promotion of breastfeeding. In the early 2000s, the prevention of mother-to-child HIV transmission programme recommended replacement feeding for infants of women living with HIV and provided free infant 
formula at public sector health facilities. ${ }^{[9]}$ A decade-long impasse in any public messaging in support of breastfeeding began, owing to fears of HIV transmission. With accumulating evidence from SA and other countries of the harmful effects of reduced breastfeeding rates on infant morbidity and mortality, ${ }^{[10-12]}$ and several revisions of World Health Organization (WHO) guidance, SA changed its policies in 2011, adopting breastfeeding as the preferred feeding choice, and in 2012 ceased providing free infant formula while scaling up access to lifelong triple antiretroviral treatment. ${ }^{[8]}$

Yet despite these policy initiatives to promote exclusive breastfeeding for the first 6 months in line with WHO guidelines, only 24\% of SA's infants are still exclusively breastfed at $4-5$ months of age, ${ }^{[13]}$ and the current rate of increase will fall short of the Global Nutrition Target of $50 \%$ exclusive breastfeeding in a country by $2025 .{ }^{[14,15]}$ This situation almost certainly contributes to SA's high under-5 mortality rate, compared with other upper- to middle-income countries, of 42 per 1000 live births, and persistently high levels of stunting. ${ }^{[13]}$ Greater multidimensional efforts in communities, health facilities and workplaces are therefore needed to promote, support and protect breastfeeding in the SA setting, particularly given concerns about the expansion of formula milk markets in the global South. ${ }^{[15]}$

SA has seen a steady growth in infant formula sales over the past 15 years, from a retail value of ZAR1 billion in 2004 to ZAR4. 2 billion in 2018 (a $33.3 \%$ per capita increase) and a forecast of over ZAR6 billion in 2023. ${ }^{[16]}$ Formula is expensive, and unaffordable for the majority of SA families. Depending on the brand, the formula alone costs an estimated ZAR375 - 561 a month, with potentially devastating implications for SA infants, $37 \%$ of whose families live below the food poverty line (households where the per capita income is $<$ ZAR531 a month). ${ }^{[17]}$ Consequently, many families opt for mixed feeding and/or dilute the formula to make it stretch further. While inadequate nutrition compromises infant health, keeping bottles clean is equally challenging, since 1 in $3 \mathrm{SA}$ infants live in households that do not have drinking water on site. ${ }^{[13,18]}$

It is therefore not surprising that gastroenteritis (9\%) and lower respiratory tract infections (17\%) continue to be leading causes of under-5 mortality. ${ }^{[19]}$ Furthermore, the most recent Child Healthcare Problem Identification Programme data show that $31 \%$ of children who died in hospital in 2015 had severe or acute malnutrition. ${ }^{[20]}$

\section{BMS industry contraventions of SA regulations to protect breastfeeding}

The National Minister of Health signed R991 into law in 2012 for full implementation within 36 months. These regulations restrict how infant formula can be advertised and labelled, as well as stipulating under which circumstances industry is allowed to contribute sponsorship for paediatric/nutrition conferences. While R991 allows the BMS industry to contribute to a pooled fund for a conference or scientific meeting, direct sponsorship of individual delegates or speakers is prohibited and R991 explicitly 'excludes any promotion of designated products' to health professionals, restricts industry involvement to scientific and technical material, and prohibits the industry from making any 'health, medicinal or nutrition claims' The National Department of Health $(\mathrm{NDoH})$ has also produced guidelines for industry and healthcare personnel relating to R991. ${ }^{[21]}$

Experience at the annual University of Cape Town Paediatric Refresher Course illustrates the extent of the problem. Between 2016 and 2018, persistent contraventions of the regulations were evident, including claims of health benefits, e.g. specific BMS brands to overcome 'Excessive Crying \& Intestinal Gas' and for 'Treatment of Diarrhoea' and 'Hungry \& Sleepless Infants' (Fig. 1), and a BMS product launch of formula milk containing human milk oligosaccharides claiming to be 'Inspired by nature's perfection' (Fig. 1) - all of this despite very clear instructions to sponsors to comply with the regulations. Similar experiences have been reported at other universities.

In 2016, North-West University's School of Pharmacy hosted a symposium at which a BMS company sponsored a 'baby nutrition' workshop. This contravention of R991 was reported to the NDoH, and the session was subsequently cancelled by the organisers following receipt of a letter outlining the R991contraventions from the Deputy Director-General: HIV/AIDS, TB and Maternal, Child and Women's Health. In July 2019, at the combined South African Thoracic Society, Allergy Society of South Africa and Chest Wall International Group conference in Pretoria, a BMS company-sponsored breakfast symposium on human milk oligosaccharides (Fig. 1) was cancelled on the morning by the symposium organisers after concerns were raised with the conference organisers and the $\mathrm{NDoH}$ regarding compliance with R991.

The BMS industry web of influence extends beyond marketing and promotion at health professional conferences, and includes a conscious intent to cultivate relationships with key thought leaders in nutrition and child health and to 'retain and reward' those who have high peer credibility and are positively disposed to the company brand. In 2012, a BMS company hired a consultancy firm to undertake a strategic stakeholder mapping exercise. The report targeted a number of thought leaders in nutrition and child health for engagement (Fig. 2). ${ }^{[22]}$ BMS industry sponsorship of universities to host nutrition symposia is an example of targeting of health professionals, such as the 14th Continuing Nutrition Education Symposium at the University of Pretoria (https://www. nestlenutrition-institute.org/country/za/) in September 2019 and similar examples from East Africa (https://www.nestlenutritioninstitute.org/country/za/news/article/2019/04/25/expansion-of-thethe-first-1-000-days-nurses-academy-by-nestl\%C3\%A9-nutritioninstitute-africa-east-africa).

The SA website of a multinational BMS company ${ }^{[23]}$ (Fig. 1) currently contains incorrect information about the risks of HIV transmission through breastfeeding and the recommendations regarding infant feeding and HIV. The website recommends that women living with HIV should formula feed for 6 months and incorrectly states the risk of HIV transmission through breastfeeding as $10 \%$ (it is currently $\sim 1 \%$ at 6 months with maternal antiretroviral therapy). ${ }^{[24]}$ This information blatantly contradicts the current SA infant and young child feeding policy, which recommends 6 months of exclusive breastfeeding for all and continued breastfeeding up to 2 years and beyond, irrespective of HIV status. ${ }^{[25]}$

The above are not isolated cases, but rather part of a global phenomenon, with a series of recent reports $^{[5]}$ documenting 'consistent, repeated, systematic violations' by the BMS industry.

\section{Conflict of interest: Understanding the potentiall risks of industry funding} It is important to recognise that conflicts of interest exist within the individual or organisation - where, for example, funding from a BMS company has the potential to undermine health workers' fiduciary duty to protect and promote child health. While we may think that researchers are objective and immune to these conflicts, a Cochrane review ${ }^{[26]}$ reported that despite academics' best intentions, conflicts of interest lead researchers to 'favour corporations either consciously or unconsciously'. This favouring does not necessarily imply collusion or corruption, but it becomes 


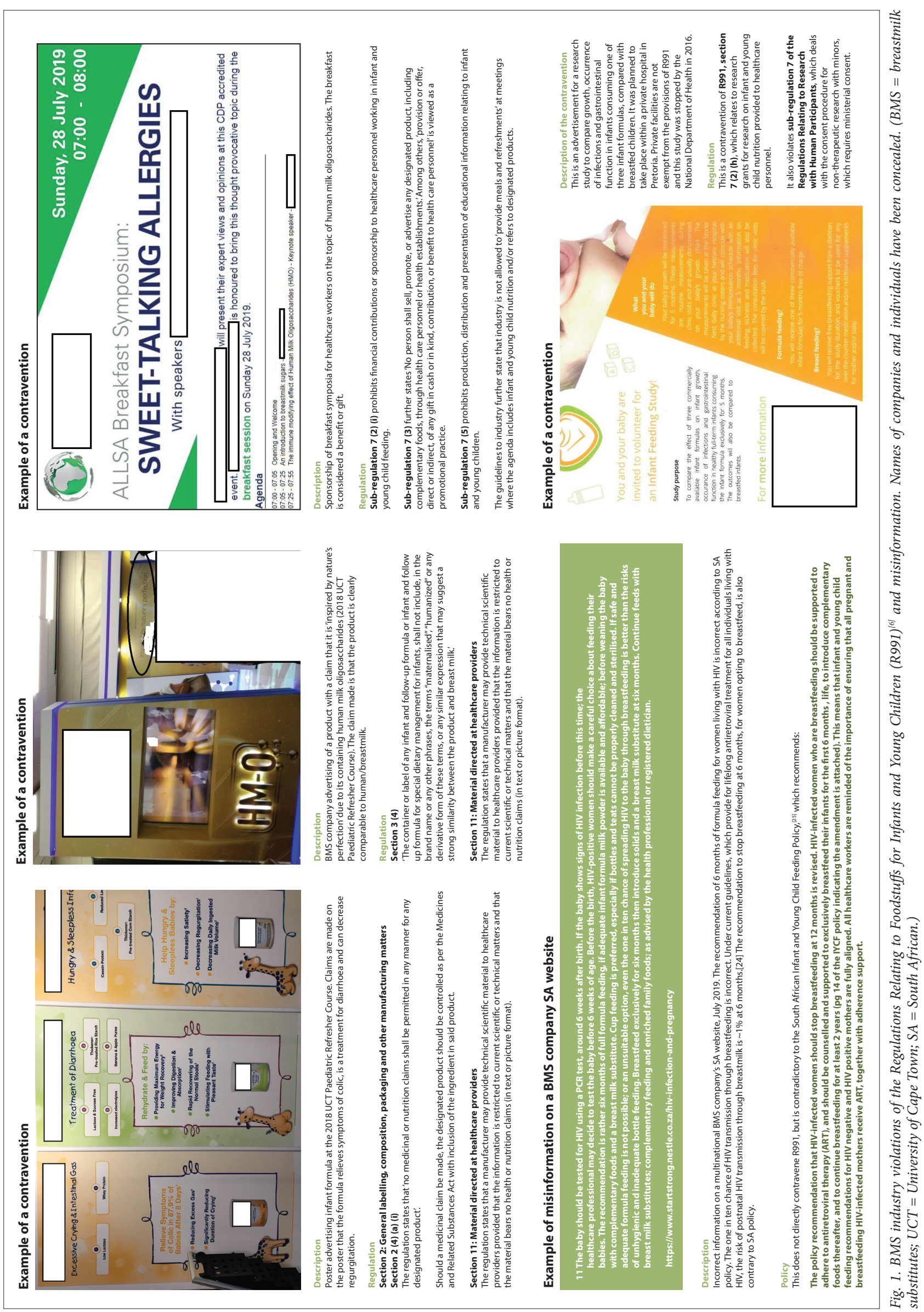




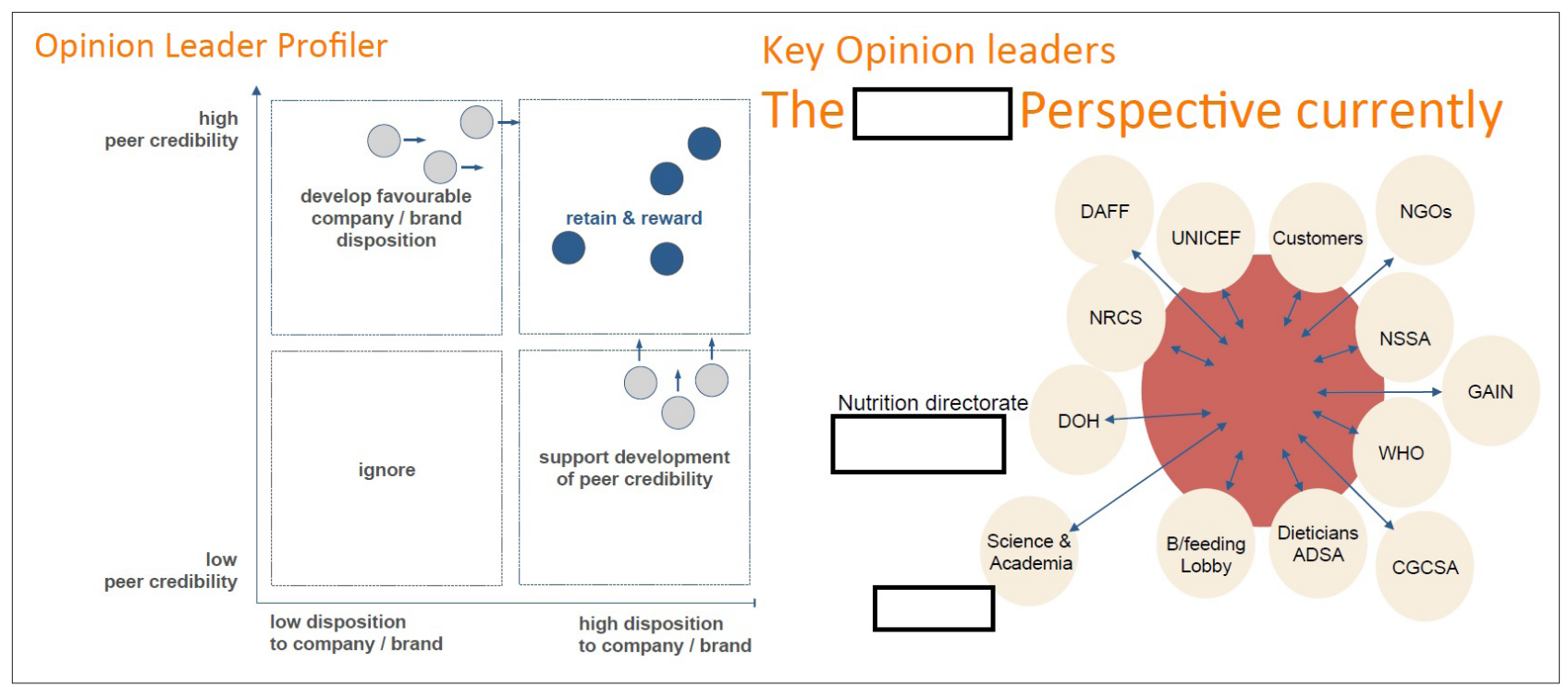

Fig. 2. BMS company stakeholder mapping. Names of individuals and the company concerned have been concealed. (BMS = breastmilk substitutes.)

'difficult to distinguish subtle, unconscious bias from deliberately concealed impropriety'.

In 2014, the International Society of Social Paediatrics and Child Health adopted a position statement calling for 'the end of all sponsorship of paediatric educational meetings by the Baby Feeding Industry' and drew attention to the potential dangers arising from various types of industry sponsorship. ${ }^{[27]}$ For example, industry sponsorship and/or branding of a child health- or nutrition-related conference creates the impression that an academic department or society publicly endorses formula feeding, while support for salaries, equipment and/or research means that a department will be indebted to the formula industry - tending to stifle any expression of doubt about the latter's products or practices.

With regard to paediatric and nutrition research, while there is indeed a place for evidence relating to the development of specialised formula milks, there are concerns about the influence of industry: a 2018 BMJ article raised concern about how 'Extensive links between the formula industry and the research, guidelines, medical education, and public awareness efforts around cow's milk protein allergy ... have raised the question of industry driven overdiagnosis.'[28] Between 2006 and 2016 in the UK, specialist formula prescriptions increased by $500 \%$ and National Health Service spending on these products increased by $700 \%$ from GBP8.1 million to GBP60 million.

It is important to recognise that these conflicts of interest extend beyond sponsorship of conferences to influence on national policy formulation and academia, where far more substantial offers of financial support may undermine the integrity of research and teaching programmes. Fig. 1 provides an example of an advertisement for a research study comparing three types of infant formula.

\section{Implementing strategies to prevent and mitigate conflicts of interest}

R991 makes provision for sanctions when its regulations are contravened. The penalties applicable to the contravention of any of the regulations are found in section 18 of the Foodstuffs, Cosmetics and Disinfectants Act. ${ }^{[7]}$ It prescribes that "[a]ny person convicted of an offence under this Act shall be liable (a) on a first conviction, to a fine or to imprisonment for a period not exceeding six months or to both a fine and such imprisonment?. Yet in SA there is minimal monitoring, reporting or enforcement. There is an urgent need for clearly defined monitoring, reporting and enforcement mechanisms that have some traction to deter contraventions. It is also unclear who, besides the BMS company, is accountable for the contravention, and the role of event organisers and organising committees, in respect of conferences and meetings, requires clarity.

So how do health professionals go about addressing conflicts of interest? A first step towards creating greater awareness and understanding of conflicts of interest is to include teaching on ethics and practice in undergraduate and in-service health professional training. By not introducing these concepts into undergraduate education, health professionals enter practice at risk of judgement errors when confronted with BMS industry influence in clinical or academic contexts. R991 applies to both the public and the private sectors, and education and awareness of the regulations and conflicts of interest are therefore needed in both sectors, particularly with the forthcoming public-private contracting proposed in SA's National Health Insurance.

From an ethical standpoint, health professionals must declare any funding, contractual relationship or in-kind support from BMS companies in any public statement, publications or conference presentations. However, the optimal approach would be to adopt a clear and unequivocal position and refuse all industry funding of child health- or nutrition-related work if health professionals are to maintain professional integrity and safeguard the health of the most vulnerable women and children.

In February 2019, after an outcry against BMS sponsorship of its conference in Cairo, the UK Royal College of Paediatrics and Child Health issued a statement announcing that it would no longer accept any funding from the formula milk industry. It would continue to 'engage and work in partnership' with formula milk companies with regard to specialist formula milks, but without accepting any funding. ${ }^{[29]}$ The College had received $\sim$ GBP40 000 a year from BMS companies through event sponsorship and advertising.

In March 2019, the BMJ (and its sister publications) stated their intent no longer to run infant formula advertisements: 'After decades of advertising breastmilk substitutes to readers of the $B M J$, we have decided it is time to stop. ${ }^{\text {[30] }}$ We call on SA health and nutrition journals to adopt similar advertising policies. 
At its recent executive meeting, the South African Paediatric Association agreed in principle not to accept any further funding from BMS companies. Bold moves such as this are what are needed to send a clear message to an industry that is adept at finding loopholes and infiltrating audiences where they know they will have the greatest impact.

Now is an appropriate time for the child health and nutrition communities to pause and reconsider any relationships with the baby food industry, including funding for research, conferences and other educational initiatives, particularly when infant feeding and allergy are involved. We therefore call on academic departments and professional associations to demonstrate their commitment to protect breastfeeding from the commercial influence of BMS companies in southern Africa, and to adopt clear position statements that signal their intention to: (i) refuse any further offers of BMS industry sponsorship for academic conferences, research or teaching programmes; (ii) disclose current sources of BMS company funding of research and teaching programmes, and require upfront disclosure of funding sources in any publications or presentations arising therefrom; (iii) take active steps to minimise the impact of any existing conflicts of interest; (iv) educate health professionals, staff and students about the benefits of breastfeeding and measures to address the conflicts of interest associated with BMS funding; $(v)$ intensify efforts to promote, support and protect breastfeeding; and (vi) monitor implementation of R991 and the Code and report any contraventions to the $\mathrm{NDoH}$.

Dedication. We dedicate this 'In Practice' article to Emeritus Professor David Sanders, who died following the acceptance of the article. David, a paediatrician and child health advocate, dedicated his life to improving the health and nutrition of children, especially the most vulnerable, through his research, writing, teaching and activism. A key focus of his work was the political economy of health and the role of transnational food companies in driving unhealthy dietary choices, including feeding of infants. The struggle for health will continue through the innumerable lives that he influenced across the globe.

Declaration. None.

Acknowledgements. None.

Author contributions. All authors contributed to the writing of the article. Funding. TD's and AG's time was supported by the South African Medical Research Council.

Conflicts of interest. None.

1. Victora CG, Bahl R, Barros AJD, et al. Breastfeeding in the 21st century: Epidemiology, mechanisms, and lifelong effect. Lancet 2016;387(10017):475-490. https://doi.org/10.1016/S0140-6736(15)01024-7

2. World Alliance for Breastfeeding Action. Breastfeeding \& sustainable development. http://waba.org. my/ (accessed 1 August 2019)

Williams C. Milk and Murder. Penang: International Organisation of Consumers Unions, 1939

4. Muller M. The Baby Killer. London: War on Want, 1974.
5. World Health Organization. Marketing of Breast-Milk Substitutes: National Implementation of the International Code, Status Report 2018. Geneva: WHO, 2018. https://www.who.int/nutrition/ publications/infantfeeding/code_report2018/en/ (accessed 1 August 2019).

6. National Department of Health, South Africa. Foodstuffs, Cosmetics and Disinfectant Act, Act 54 National Department of Health, South Africa. Foodstuffs, Cosmetics and Disinfectant Act, Act 54
of 1972. Regulations relating to foodstuffs for infants and young children. Government Notice No. of 1972. Regulations relating to foodstuffs for infants and young children. Government Notice No.
R. 991, 2012. http://blogs.sun.ac.za/iplaw/files/2013/12/ZAF-2012-Regulations-relating-to-foodstuffsR. 991, 2012. http://blogs.sun.ac.za/iplaw/files/2013/12/ZAF-2012-Regulations-relating-to-for
for-infants-and-young-children-R.-No.-991-of-2012_0.pdf (accessed 31 October 2019).

7. Republic of South Africa. Foodstuffs, Cosmetics and Disinfectant Act, Act 54 of 1972 . https://www.gov za/documents/foodstuffs-cosmetics-and-disinfectants-act-2-jun-1972-0000 (accessed 5 August 2019). National Department of Health, South Africa. Tshwane Declaration of Support for Breastfeeding in South Africa. 2011. http://www.sajcn.co.za/index.php/SAJCN/article/view/586 (accessed 1 July 2019).

9. Doherty T, Sanders D, Goga A, Jackson D. Implications of the new WHO guidelines on HIV and infant feeding for child survival in South Africa. Bull World Health Organ 2011;89(1):62-67. https:// doi.org/10.2471/BLT.10.079798

10. Rollins NC, Becquet R, Bland RM, Coutsoudis A, Coovadia HM, Newell M-L. Infant feeding HIV transmission and mortality at 18 months: The need for appropriate choices by mothers and prioritization within programmes. AIDS 2008;22(17):2349-2357. https://doi.org/10.1097/ QAD.0b013e328312c740

11. Doherty T, Chopra M, Jackson D, Goga A, Colvin M, Persson LA. Effectiveness of the WHO/UNICEF guidelines on infant feeding for HIV-positive women: Results from a prospective cohort study in South Africa. AIDS 2007;21(13):1791-1797. https://doi.org/10.1097/QAD.0b013e32827b1462

12. Creek TL, Kim A, Lu L, et al. Hospitalization and mortality among primarily nonbreastfed children during a large outbreak of diarrhea and malnutrition in Botswana, 2006. J Acquir Immune Defic Syndr 2010;53(1):14-19. https://doi.org/10.1097/QAI.0b013e3181bdf676

13. National Department of Health, South Africa/Statistics South Africa/South African Medical Research Council/ICF. South Africa Demographic and Health Survey 2016. Pretoria: National Department of Health, 2019. http://www.mrc.ac.za/reports/SADHS2016 (accessed 10 August 2019).

14. World Health Organization (WHO)/United Nations Children's Fund (UNICEF). Global Nutrition Targets 2025: Breastfeeding Policy Brief (WHO/NMH/NHD/14.7). Geneva: WHO, 2014. https://www. who.int/nutrition/publications/globaltargets2025_policybrief_breastfeeding/en/ (accessed 15 Augus 2019).

15. Rollins NC, Bhandari N, Hajeebhoy N, et al. Why invest, and what it will take to improve breastfeeding practices? Lancet 2016;387(10017):491-504, https://doi.org/10.1016/S0140-6736(15)01044-2

16. Euromonitor International. Milk Formula in South Africa: Datagraphics. London: Euromonitor International, 2018 .

17. Sambu W. Analysis of the General Household Survey 2017. Cape Town: Children's Institute, University of Cape Town, 2018

18. Andresen E, Rollins NC, Sturm AW, Conana N, Greiner T. Bacterial contamination and over-dilution of commercial infant formula prepared by HIV-infected mothers in a prevention of mother-to-child transmission (PMTCT) programme, South Africa. J Trop Pediatr 2007;53(6):409-414. https://doi. org/10.1093/tropej/fmm059

19. United Nations Children's Fund (UNICEF). Countdown to 2030 South Africa Country Profile. New York: UNICEF, 2016. http://profiles.countdown2030.org/\#/cp/ZAF (accessed 15 June 2019).

20. National Department of Health, South Africa. 3rd Triennial report of the Committee on Morbidity and Mortality in Children under 5 Years (CoMMiC): 2015 - 2017. Pretoria: NDoH, 2017.

21. National Department of Health, South Africa. Guidelines to Industry and Health Care Personnel: The Regulations Relating to Foodstuffs for Infants and Young Children, R991 of 6 December 2012 ('Regulations'). https:/www foodfocusco And-Health-Care-Personnel-The-Regulations-Relating-To-Foodstuffs-For-Infants-And-YoungAnd-Health-Care-Personnel-The-
Children (accessed 22 June 2019).

22. Sahara Salt Consulting. Nestle Nutrition South Africa Stakeholder Mapping. 2012. http://www.nestle. Sahara Salt Consulting. Nestle Nutrition South Africa Stakeholder Mapping. 2012. http://www.nestle,
co.za/Common/NestleImages/PublishingImages/Documents/About/nestle_11122012update.pdf co.za/Common/Nestlel

(accessed 2 August 2019)

23. Nestle South Africa. HIV infection and pregnancy. 2019. https://www.startstrong.nestle.co.za/hivinfection-and-pregnancy (accessed 22 July 2019).

24. Bispo S, Chikhungu L, Rollins N, Siegfried N, Newell M-L. Postnatal HIV transmission in breastfed infants of HIV-infected women on ART: A systematic review and meta-analysis. J Int AIDS Soc 2017;20(1):21251. https://doi.org/10.7448/IAS.20.1.21251

25. National Department of Health, South Africa. Circular minute number 3 of 2017/18 HIV/AIDS, TB MNCWH: Amendment of the 2013 infant and young child feeding (IYCF) policy. Pretoria: NDoH, 2017.

26. Lundh A, Lexchin J, Mintzes B, Schroll JB, Bero L. Industry sponsorship and research outcome. Cochrane Database Syst Rev 2017, Issue 2. Art. No.: MR000033. https://doi.org/10.1002/14651858. MR000033.pub3

27. International Society for Social Pediatrics and Child Health. ISSOP Declaration: Conflict of Interes and Funding from the Baby Food Industry. 2019. https://www.issop.org/2019/03/26/issop-declarationand Funding from the Baby Food Industry. 2019. https://wWw.issop.org/2019/03/26/issop
conflict-of-interest-and-funding-from-the-baby-food-industry/ (accessed 25 July 2019).

28. Van Tulleken C. Overdiagnosis and industry influence: How cow's milk protein allergy is extending . Van Tulleken C. Overdiagnosis and industry influence: How cows milk protein allergy is extendin
the reach of infant formula manufacturers. BMJ 2018;363:k5056. https://doi.org/10.1136/bmj.k5056 the reach of infant formula manufacturers. BMJ 2018;363:k5056. https://doi.org/10.1136/bmj.k5056
Mayor S. Royal college stops taking funding from formula milk firms. BMJ 2019;364:1743. https://doi. Mayor S. Royal college
org $/ 10.1136 /$ bmj.1743

30. Godlee F, Cook S, Coombes R, El-Omar E, Brown N. Calling time on formula milk adverts. BM] 2019;364:11200. https://doi.org/10.1136/bmj.11200

Accepted 2 September 2019 